\title{
Persistent effects of acute stress on fear and drug- seeking in a novel model of the comorbidity between post-traumatic stress disorder and addiction
}

\author{
Christie L. Pizzimenti, Tom M. Navis, and K. Matthew Lattal \\ Department of Behavioral Neuroscience, Oregon Health \& Science University, Portland, Oregon 97239, USA
}

\begin{abstract}
Even following long periods of abstinence, individuals with anxiety disorders have high rates of relapse to drugs of abuse. Although many current models of relapse demonstrate effects of acute stress on drug-seeking, most of these studies examine stressful experiences that occur in close temporal and physical proximity to the reinstatement test. Here, we assess the effects of a stressful experience in one context on fear and drug-seeking in a different context. We adapt the stress-enhanced fear learning procedure to examine impacts on drug-seeking long after the stressful experience occurred. We find massive footshock in a distinct environment produced an acute increase in corticosterone, long-term hyper-responsivity to a single shock in different contexts with extensive histories of drug-seeking behaviors, enhancements in cocaineinduced conditioned place preference in mice, and persistent enhancements in cue-induced reinstatement of methamphetamine-seeking behavior in rats. Together, these experiments demonstrate that an acute trauma causes persistent changes in responsivity to mild stressors and drug-seeking behavior in other contexts, which mirrors aspects of the comorbidity between post-traumatic stress disorder and substance use disorders. These behavioral approaches provide novel procedures for investigating basic mechanisms underlying this comorbidity and they provide powerful tools for testing preclinical pharmacological and behavioral interventions.
\end{abstract}

[Supplemental material is available for this article.]

Compared with the general population, individuals diagnosed with post-traumatic stress disorder (PTSD) have higher rates of substance use disorders (SUDs) (Stewart 1996; McFarlane 1998; Ouimette et al. 1998; Back et al. 2000; Sonne et al. 2003; McCauley et al. 2012; Tipps et al. 2014; Roberts et al. 2015) and are twice as likely to use methamphetamine (METH) than are individuals with trauma exposure that does not lead to PTSD (Smith et al. 2010). Individuals with PTSD are also more likely to relapse to drugs of abuse when cues associated with drug-seeking are encountered, even long after periods of acute stress have ended (Bradizza et al. 2006), suggesting stressors that are temporally and contextually dissociated from drug-seeking may induce longterm changes that contribute to an increased risk for relapse.

It has long been observed that stress is a potent inducer of reinstatement (an animal model of relapse) in rodents (e.g., Shaham et al. 2000; Erb et al. 2001; Sanchez and Sorg 2001; Boutrel et al. 2005; Redila and Chavkin 2008; Schindler et al. 2010). Although the ability of stress to induce reinstatement has been well established in the literature, most studies have focused on effects when the organism is tested in a state of acute stress within the drug-seeking context; few studies have evaluated the persistent effects of an acute stressor long after the stress has ended. Individuals with PTSD have traumatic experiences long before relapse and are unlikely to use drugs in the trauma-associated context; avoiding the location in which the trauma occurred is one of the DSM criteria for a diagnosis of PTSD (American Psychiatric Association 2013). Stressors that occur within a distinct environment (e.g., social defeat; Quadros and Miczek 2009) or are administered repeatedly (e.g., chronic tail pinch; Piazza et al. 1990) have been

\section{Corresponding author: lattalm@ohsu.edu}

Article is online at http://www.learnmem.org/cgi/doi/10.1101/lm.044164.116. shown to increase acquisition of drug self-administration, but comparatively little is known about how an acute stressor causes persistent changes in drug-seeking responses long after that stressful experience has ended. Developing a model of this persistence is key to understanding the PTSD-SUD comorbidity and to evaluating novel treatment interventions for both disorders.

There is evidence that an acute stressor (a battery of footshocks) associated with a specific environment can have lasting effects on fear responses to a mild stressor (a single footshock) in a different environment (Rau et al. 2005). This stress-enhanced fear learning (SEFL) persists across long intervals (Rau and Fanselow 2009) and shows properties that differ from weaker forms of fear conditioning, such as resistance to extinction (Long and Fanselow 2012) and NMDA receptor independence (Rau et al. 2005). An advantage of the SEFL approach is that it incorporates a fear conditioning procedure that has been characterized extensively at behavioral, cellular, and molecular levels (Kim and Jung 2006; Maren et al. 2013), resulting in a stress procedure that has measureable memory and affective components (for review, see Blouin et al. 2016). This procedure results in the same wellcharacterized behavioral response (conditioned freezing) both in the original stressful context and in novel contexts in which a single shock is encountered. Thus, the persistence of the stress response over time can be measured and manipulated in behaviorally tractable ways.

\footnotetext{
(C) 2017 Pizzimenti et al. This article is distributed exclusively by Cold Spring Harbor Laboratory Press for the first 12 months after the full-issue publication date (see http://learnmem.cshlp.org/site/misc/terms.xhtml). After 12 months, it is available under a Creative Commons License (AttributionNonCommercial 4.0 International), as described at http://creativecommons. org/licenses/by-nc/4.0/.
} 
A

\begin{tabular}{l|cccc} 
A & $\begin{array}{c}0,1,4 \text {, or } 15 \\
\text { footshocks }\end{array}$ & $\begin{array}{c}\text { Context } \\
\text { A Test }\end{array}$ & $\begin{array}{c}1 \text { footshock in } \\
\text { Context B }\end{array}$ & Context B Test \\
\hline $\begin{array}{l}\text { Exp. Day } \\
\text { Context }\end{array}$ & 1 & 2 & 3 & 4 \\
\cline { 2 - 5 } & A & A & B & B
\end{tabular}

B

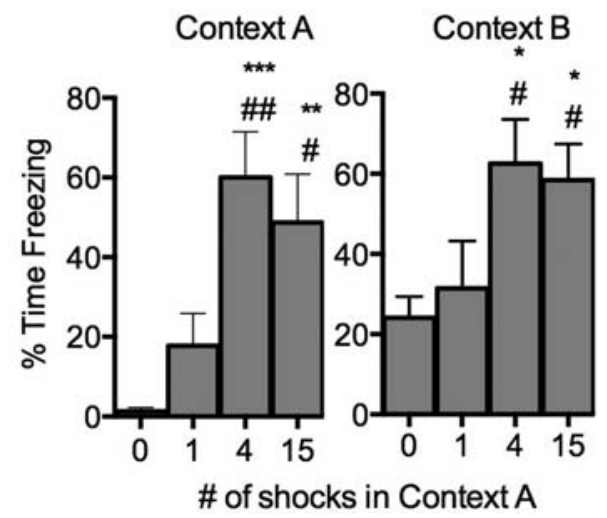

Figure 1. The stress-enhanced fear learning (SEFL) effect. $(A)$ Overview of the design of Experiment 1. Rats received $0(n=5), 1(n=5), 4(n=$ $5)$, or $15(n=6)$ shocks in Context A, followed by a single shock in Context B. Retention was tested in both contexts. (B) Animals that receive 4 or 15 shocks, but not 0 or 1 shocks in Context $A$ demonstrate enhancements in freezing following a single shock in Context $\mathrm{B} .\left(^{*}\right) P<0.05$, $\left.{ }^{* *}\right) P<0.01,\left({ }^{* * *}\right) P<0.001$ relative to 0 shocks, (\#) $P<0.05$, (\#\#) $P<0.01$ relative to 1 shock.

In the following experiments, we characterize the effects of a battery of footshocks in one context on exaggerated fear and drug-seeking responses in another context. We show that the basic SEFL effect occurs in contexts that have an extensive history of association with drugseeking. Further, we find that a battery of footshocks in one context causes persistent effects on cue-induced reinstatement and subsequent resistance to extinction of drug-seeking in another context. Together, these findings show that a single acute trauma causes a hyperresponse to a mild stressor and enhances cue-induced reinstatement long after that trauma. This model opens the doors to testing new treatment options for the comorbidity between PTSD and SUDs.

\section{Results}

\section{Experiment 1: replication of the SEFL} effect

In Experiment 1 (overview shown in Fig. 1A), we replicated the basic SEFL effect: rats that received 4 or 15 footshocks in Context A showed higher freezing during tests in Contexts A and B compared with rats receiving 0 or 1 footshock (Fig. 1B; reliable main effects of group during Context A $\left(F_{(3,17)}=7.60, P=0.002\right)$ and Context B tests $\left.\left(F_{(3,17)}=3.97, P=0.026\right)\right)$. There were no significant differences between the 0 and 1 shock groups $(P>$ 0.257 ) or between the 4 and 15 shock

A

B

\begin{tabular}{l|ccccc|} 
& Acquisition & Maintenance & Extinction & Massive Shock & Single Shock \\
\hline Exp. Day & $1-10$ & $11-28$ & $29-31$ & 32 & 33 \\
Context & METH & METH & METH & SHOCK & METH \\
\cline { 2 - 5 }
\end{tabular}

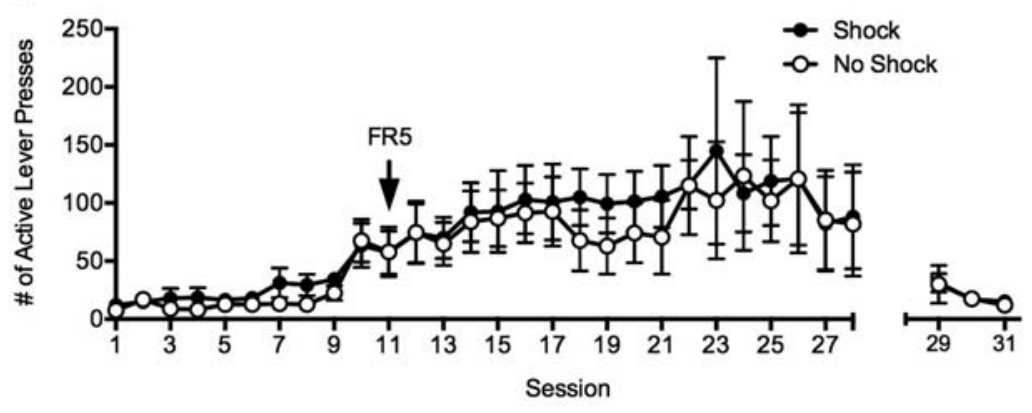

C

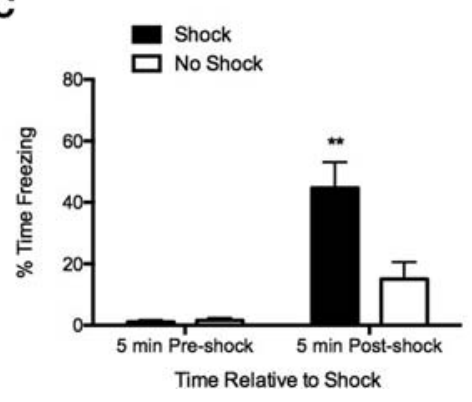

groups $(P>0.41)$ in either test. However, there was a significant difference between 0 and 1 shock groups compared with the 4 shock $(P s<0.05)$ and the 15 shock group $(P s<0.05)$ in both tests.

\section{Experiment 2: SEFL effect in a context associated with methamphetamine}

In Experiment 2 (overview shown in Fig. 2A), we found that massive footshock in a different context (SHOCK) following extinction of self-administration caused a SEFL effect in the drug-seeking context $(\mathrm{METH})$ but did not reinstate drug-seeking behavior. There were no reliable main effects of group or interactions involving group during acquisition, maintenance, or extinction (Fig. 2B; see Supplemental Table S1 in Supplemental Information). Animals that received massive footshock in the SHOCK context showed higher freezing in the 5 min following a single footshock in the METH context (Fig. 2C; main effect of group $\left(F_{(1.11)}=7.40\right.$, $P<0.01)$, time $\left(F_{(1.11)}=31.7, P<0.0001\right)$, and a significant interaction $\left.\left(F_{(1.11)}=8.8, P=0.01\right)\right)$; animals that had previously received massive footshock froze significantly more following exposure to a single shock than did exposure only controls $\left(t_{(11)}=2.87, P=0.01\right)$.

The single footshock did not induce reinstatement of methamphetamine seeking in either group (Fig. 2D). Analysis of the last day of extinction and the single footshock session revealed a decrease in lever pressing (main effect of session, $\left(F_{(1,11)}=17.27\right.$, $P<0.01))$ and a significant main effect of lever $\left(F_{(1,11)}=7.63, P<\right.$ $0.05)$. 


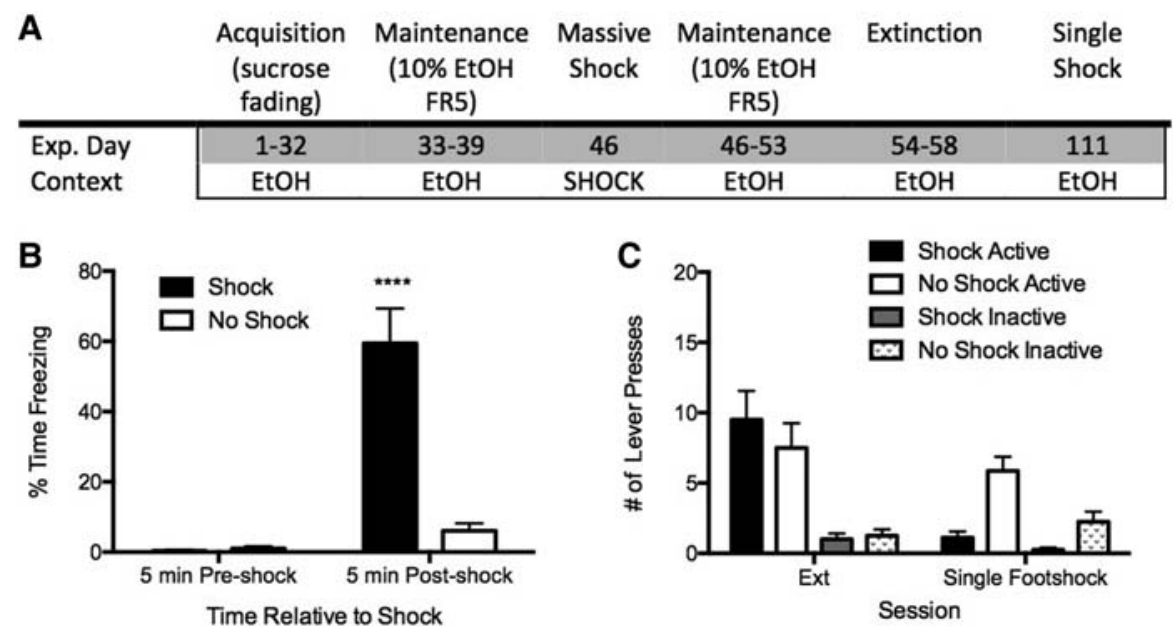

Figure 3. Effects of SEFL on freezing and reinstatement in a context associated with alcohol selfadministration. $(A)$ Overview of the design of Experiment 3. Rats were trained to respond for ethanol following a sucrose fading procedure and received 0 (Group No Shock; $n=8$ ) or 15 shocks (Group Shock; $n=8)$ in a different context during the maintenance phase. The SEFL test occurred in the ethanol-associated context after a long retention interval. $(B)$ Freezing in the alcohol-associated context before and after both groups received the single shock. (C) Responding on active and inactive levers during the final extinction session and during the single shock reinstatement session. $\left(^{\star \star \star *}\right) P<0.0001$.

\section{Experiment 3: SEFL effect in a context associated with ethanol}

In Experiment 3 (overview shown in Fig. 3A), we found that massive footshock in a different context (SHOCK) caused an exaggerated fear response in the ethanol-seeking context (EtOH), even after that context had been associated with EtOH for over $60 \mathrm{~d}$. There were no effects of shock on maintenance or extinction of ethanolseeking (data not shown). Analysis of freezing before and after the single shock in the EtOH context (Fig. 3B) revealed a significant main effect of group $\left(F_{(1.14)}=27.20, P<0.0001\right)$, time $\left(F_{(1.14)}=\right.$ $39.20, P<0.0001)$, and a significant interaction $\left(F_{(1.14)}=27.80, P\right.$ $<0.0001)$ such that animals with a history of footshock in Context A froze more than did exposure only controls $\left(t_{(13)}=\right.$ $4.85, P<0.0001)$.

As in Experiment 2, the SEFL effect did not induce reinstatement (Fig. 3C). Analysis of the last day of extinction and the single footshock session revealed a significant main effect of session $\left(F_{(1,14)}=33.004, P<0.0001\right)$ such that lever pressing decreased overall, lever $\times$ group $\left(F_{(1,14)}=13.72, P<0.001\right)$, session $\times$ lever $\left(F_{(1,14)}=16.35, P<0.001\right)$, but not session $\times$ group $\left(F_{(1,14)}=0.022\right.$, $P=0.884)$, nor lever $\times$ session $\times$ group interactions $\left(F_{(1,14)}=3.89\right.$, $P>0.05)$.

The high levels of freezing in Experiments 2 and 3 likely prevented any effect of the single shock on reinstatement to be observed. Consequently, in Experiment 4, we attempted to induce reinstatement with acute manipulations that should not result in a freezing response, such as brief restraint or exposure to drug-associated cues.

Experiment 4: massive footshock during acquisition of methamphetamine self-administration in a different context causes an enhancement in cue-induced reinstatement

and a resistance to extinction

In Experiment 4 (overview shown in Fig. 4A), there were no effects of shock on late acquisition, maintenance, or extinction of drugseeking (Fig. 4B; no reliable main effects of group or interactions involving group; see Supplemental Tables S2, S3 in Supplemental mals that hadion $\left(F_{(1,9)}=5.36, P=0.04\right)$. The animats received footshock on Day 15 pressed significantly more on the active lever compared with exposure only controls during cue-induced reinstatement on Day $39\left(t_{(9)}=2.4, P<0.05\right.$; Fig. 4D). The difference between groups during cue-induced reinstatement persisted through extinction that followed the cue test (Fig. 5A; reliable session $\times$ lever $\times$ group interaction $\left(F_{(5,45)}=2.46\right.$, $P<0.05)$ with higher active lever presses in the shock group).

Following extinction animals remained in the homecage for 5 $\mathrm{d}$ and were then tested for retention. Analysis of the retention test day and the last extinction session ( $6 \mathrm{~d}$ prior) revealed a significant main effect of session $\left(F_{(1,9)}=29.14, P<0.001\right)$, lever $\left(F_{(1,9)}=51.50\right.$, $P<0.001)$, and session $\times$ lever $\left(F_{(1,9)}=59.50, P<0.001\right)$ such that both groups of animals significantly increased active lever pressing following a 5-d retention interval (Fig. 4E).

The animals that received footshock maintained higher levels of responding compared with exposure only controls following the retention test (Fig. 5B; significant main effect of session $\left(F_{(12,108)}=2.36, P<0.01\right)$, lever $\left(F_{(1,9)}=11.7, P<0.01\right)$, session $\times$ group $\left(F_{(12,108)}=2.44, P<0.01\right)$, and session $\times$ lever interactions $\left(F_{(12,108)}=3.23, P<0.01\right)$ during the 13 post-retention extinction sessions), as well as a trend toward a session $\times$ group $\times$ lever interaction $\left(F_{(12,108)}=2.5, \quad P=0.069\right)$. Analysis of the footshockinduced reinstatement session and the previous extinction session revealed a significant main effect of session $\left(F_{(1,9)}=7.31, P\right.$ $=0.02)$ and a significant effect of group $\left(F_{(1,9)}=5.09, P=0.05\right.$; Fig. $4 \mathrm{~F})$ with no other significant main effects or interactions (Fig. 4F).

\section{Experiment 5: massive footshock prior to acquisition of methamphetamine seeking enhances cue-induced reinstatement and post-reinstatement responding} In Experiment 5 (overview shown in Fig. 6A), we found that exposure to the battery of footshocks prior to acquisition of methamphetamine seeking increased cue-induced reinstatement after extinction 3 wk later (Fig. 6C). Massive footshock had no effect on acquisition, maintenance, or extinction of responding for methamphetamine (Fig. 6B; no reliable main effects of group or interactions involving group; see Supplemental Table S6 in Supplemental Information). A RM ANOVA conducted on the last day of 
A

\begin{tabular}{|c|c|c|c|c|c|c|c|c|c|c|c|c|}
\hline & Acq. & FS & Main. & Ext & RIR & Ext & CIR & Ext & $\mathrm{HC}$ & RET & Ext & FIR \\
\hline & $1-14$ & 15 & $15-30$ & $31-33$ & 34 & $35-38$ & 39 & $40-45$ & $46-50$ & 51 & $52-64$ & 65 \\
\hline Context & METH & Shock & METH & METH & METH & METH & METH & METH & $\mathrm{HC}$ & METH & METH & METH \\
\hline
\end{tabular}

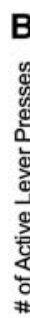

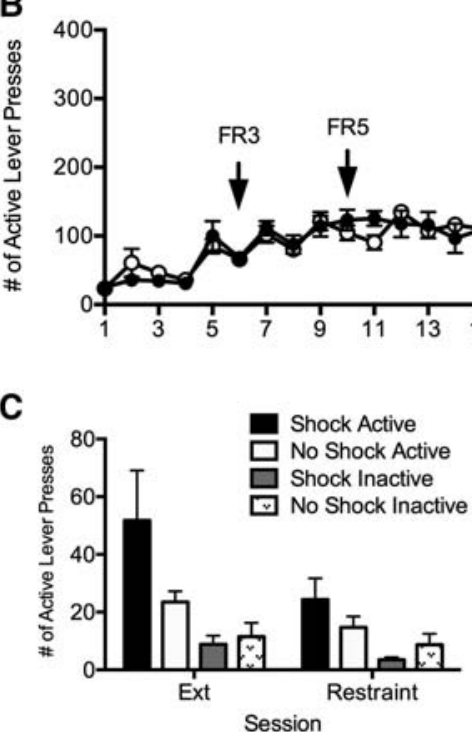

E

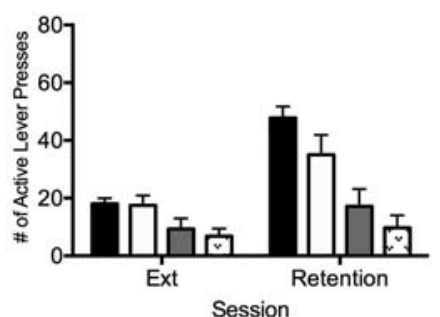

$\rightarrow$ Shock

- No Shock

\section{FR10}

$\downarrow$

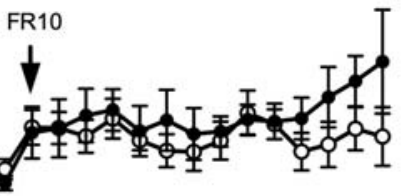

Session

D

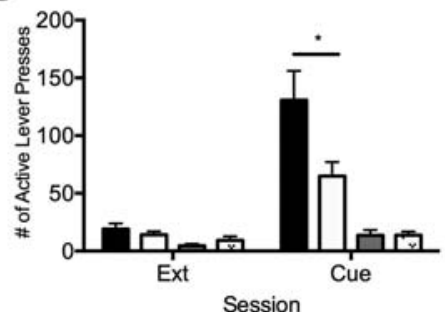

$\mathbf{F}$

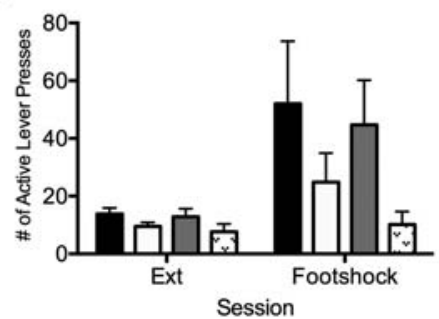

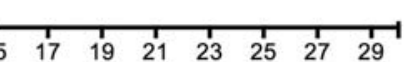

Figure 4. Effects of shock delivered during the course of acquisition of methamphetamine seeking on long-term tests of reinstatement. $(A)$ Overview of the design of Experiment 4. Rats received 0 (Group No Shock; $n=5$ ) or 15 shocks (Group Shock; $n=6$ ) in a different context during the maintenance phase. Following extinction, rats received several tests for reinstatement: restraint-induced reinstatement (RIR), cue-induced reinstatement (CIR), retention (RET), and footshock-induced reinstatement (FIR). Each reinstatement test was preceded by at least three additional extinction sessions. (B) Acquisition and extinction of methamphetamine self-administration. (C) Restraint-induced reinstatement. (D) Drug cue-induced reinstatement. $(E)$ Spontaneous recovery retention test. $(F)$ Footshock-induced reinstatement. (*) $P<0.05$.

extinction and cued reinstatement revealed a main effect of lever $\left(F_{(1,13)}=10.31, P<0.01\right)$, session $\left(F_{(1,13)}=52.39, P<0.001\right)$, lever $\times$ session $\left(F_{(1,13)}=16.54, \quad P<0.001\right)$, and lever $\times$ session $\times$ group $\left(F_{(1,13)}=4.99, P<0.05\right)$; animals with a history of footshock pressed the active lever significantly more than exposure only controls $\left(t_{(13)}=1.83, P<0.05\right.$; Fig. $\left.6 \mathrm{C}\right)$. In a final extinction session $24 \mathrm{~h}$ following cued reinstatement, responding on the active $(P<0.01)$, but not the inactive $(P=0.14)$ lever was significantly higher in animals with a history of footshock relative to exposure only controls (Fig. $6 \mathrm{D})$.

\section{Experiment 6: massive footshock}

in a different context prior to cocaine-induced conditioned place preference (CPP)

In Experiment 6 (overview shown in Fig. 7A), we found that mice with a history of footshock showed enhanced expression of cocaine-induced CPP during preference tests conducted immediately and $24 \mathrm{~h}$ after footshocks. As can be seen in Figure 7B, there were no differences between groups in activity during pretest or during the conditioning trials $(\mathrm{CS}+$ or CS-). During pretest and conditioning, there was no reliable main effect of group $\left(F_{(1,38)}=0.005, P=0.954\right)$ or group $\times$ session interaction $\left(F_{(1,38)}=2.73, P=0.10\right)$, but there was a main effect of session $\left(F_{(1,38)}=247.33, \quad P<0.0001\right)$, with increased activity during cocaine conditioning trials $(\mathrm{CS}+)$. Following the shock, there again were no group differences in activity during the preference tests $(P \mathrm{~s}>0.05)$.

Relative to No Shock controls, mice with a history of footshocks showed increased preference immediately (Test 1 ) and $24 \mathrm{~h}$ later (Test 2; Fig. 7C; reliable main effect of group $\left(F_{(1,34)}=5.42, P=\right.$ $0.01)$, no main effect of session or interaction $(P s>0.05)$.

\section{Experiment 7: the effect of massive footshock on corticosterone (CORT) and hypothalamic- pituitary-adrenal axis function}

In Experiment 7 (overview shown in Fig. $8 \mathrm{~A}$ ), we found that animals that received 15 footshocks demonstrated significantly elevated levels of CORT relative to No Shock controls immediately following footshock (Fig. 8). A RM ANOVA revealed a significant main effect of session $\left(F_{(6,72)}\right.$ $=6.47, P<0.0001)$ as well as group $\left(F_{(1,72)}\right.$ $=4.36, \quad P=0.05)$, but no interaction $\left(F_{(6,72)}=1.46, P=0.2\right.$; Fig. 8B). Follow-up analyses found that groups did not differ on any blood draw (Ps >0.05) except the one immediately following footshock $(P$ $<0.01$ ). Dexamethasone (DEX) administration attenuated the HPA response in both groups, with a significant main effect of drug (DEX versus Veh; $F_{(1,24)}=26$, $P<0.0001)$ and no main effect of group or interactions (Ps >0.05; Fig. 8C).

Forty-eight days following 0 or 15 footshocks in Context A animals with a history of shock demonstrated significantly elevated freezing when re-exposed to that context $\left(F_{(1,12)}=125.29, P<0.001\right)$, as well as significantly elevated freezing in Context $\mathrm{B}$ the day after receiving a single footshock in that context $\left(F_{(1,12)}=8.87, P=0.01\right)$.

\section{Discussion}

These experiments show a consistent and long-lasting effect of exposure to a bout of massive footshocks in one context on fear and drug-seeking in another context. This occurred when the shock occurred prior to or during acquisition of methamphetamine selfadministration in rats and after acquisition of cocaine-induced CPP in mice. Our findings also extend the basic stress-enhanced fear learning (SEFL) effect to show that it persists up to $60 \mathrm{~d}$ after the initial battery of shocks and that it can be revealed in a drugseeking context even after 30 (METH) or 60 (EtOH) daily 2 h sessions, suggesting that an extensive history of drug associations with a context does not prevent that context from revealing a SEFL effect. Together, these results suggest that this combination of massive fear conditioning and cue-induced reinstatement of 

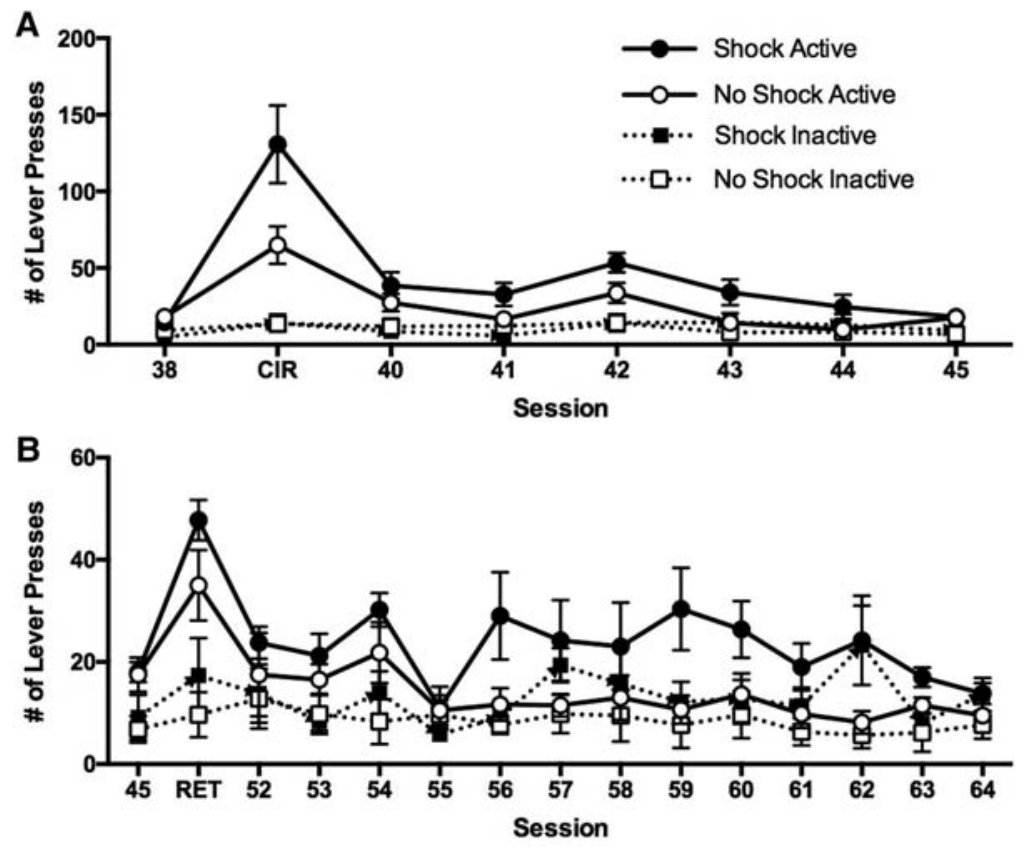

Figure 5. Persistent effects of shock on resistance to extinction of methamphetamine seeking following cue-induced reinstatement in Experiment 4. (A) Active lever pressing during the final extinction session before cue-induced reinstatement (CIR) and during six post-reinstatement extinction sessions. (B) Active lever pressing during the final extinction session before the retention test (RET; Session 51) and the 13 post-retention extinction sessions. $\left({ }^{*}\right) P<0.05$.

drug-seeking provides a strong preclinical model of the comorbidity between PTSD and substance use disorders.

It is notable that when the SEFL effect on freezing was observed, there were no effects of the single shock on reinstatement of extinguished responding. The single shock used in our SEFL procedure resulted in a strong freezing response, which was particularly true in Experiment 3 in which the single footshock completely suppressed lever pressing in the group that previously received the battery of footshocks. That likely occurred because the freezing response prevented the animals from engaging in the instrumental drug-seeking response and is consistent with many studies showing an inability of animals to perform instrumental actions in a state of high fear (e.g., Bouton and Bolles 1980).

In Experiment 4, we aimed to reveal an effect of the massive battery of footshocks on the reinstatement of drug-seeking behavior that was not confounded by differences in a freezing response during the reinstatement session. We therefore evaluated several tests that may result in a reinstatement or return of drug-seeking. We found that regardless of shock history, brief restraint did not reinstate drug-seeking. Previous literature has demonstrated mixed effects of restraint to induce reinstatement of drug-seeking (Shaham 1993; Shalev et al. 2000; Sanchez et al. 2003). However, allowing time to pass between extinction and a subsequent test did cause spontaneous recovery of drug-seeking in both groups. When footshocks were massed closely together within the selfadministration context, there was reinstatement, but this was not specific to the active lever, which is consistent with findings that shocks evoke general activity both during and soon after their presentation (Fanselow 1982). Although other studies have documented shock-induced reinstatement, the specificity of this effect to the drug-seeking lever is not always clear (see Shaham et al. 1998; Lê et al. 1999; Liu and Weiss 2002; McFarland et al. 2004).

Our most consistent finding was that massive footshocks outside of the drug-seeking contexts resulted in an increase in cue-induced reinstatement or expression of cue-associated CPP (Experiments 4-6) even though the shocks did not immediately alter acquisition, maintenance, or extinction of drug-seeking behaviors. In general, effects on drug-seeking that have been revealed during acquisition involve repeated stressors (e.g., Goeders and Guerin 1994; Lewis et al. 2013). Shaham and Stewart (1994) found that intermittent footshock prior to several daily self-administration sessions increased the progressive ratio breakpoint for heroin. Other work has shown that stressors administered outside of the drug-associated context, including chronic tail pinch (Piazza et al. 1990), social defeat (Tidey and Miczek 1997), or exposure to a hot plate or repeated footshocks (Ramsey and Van Ree 1993) increase acquisition of self-administration. A more recent report in a procedure similar to ours found that repeated exposures to predator odor over $5 \mathrm{~d}$ had no effects on acquisition or extinction of methamphetamine seeking, but resulted in enhanced cue-induced reinstatement (Ferland et al. 2016). Thus, there is precedent for observing an effect that is specific to cue-induced reinstatement, but it remains possible that our specific parameters for acquisition or extinction were not sensitive enough to reveal differences as a function of history of shock. Exploring different response requirements or session durations would be useful for future characterizations of these effects.

The novelty of our findings is that a single, acute stressor delivered outside of the self-administration context resulted in persistent effects on drug-seeking in a different context. The effects were similar when the acute stressor occurred prior to acquisition or during maintained responding for methamphetamine. A study by Meyer et al. (2013) found that the same acute, massive shock stressor used here causes persistent changes in alcohol consumption, but only in those animals that had not established drinking patterns prior to shock. Determining how this shock stressor interacts with drug taking, drug-seeking, and previous drug history will be important next steps in evaluating this model of comorbidity.

In humans, it has been repeatedly reported that individuals that are comorbid for PTSD and SUDs do not differ from individuals with SUDs alone in substance use severity (Brown Stout and Mueller 1999; Eggleston et al. 2009), but are more likely to relapse (Tate Brown Unrod and Ramo 2004; Kubiak 2004; Burns et al. 2010; Najt Fusar-Poli and Brambilla 2011). This is corroborated by the findings in our experiments of no differences in acquisition or maintenance between previously shocked or unshocked rats, but shocked rats showed greater reinstatement after successful extinction. This specificity to cue-induced reinstatement makes this model a potentially powerful tool to model the comorbid condition.

One particularly interesting finding from our experiments was that even though Shock and No Shock groups did not differ at any point prior to cue-induced reinstatement, the differences that occurred during the reinstatement session persisted during subsequent drug- and cue-free tests. In Experiment 4, shocked animals continued to show elevated responding over spontaneous recovery tests and additional extinction sessions up to $25 \mathrm{~d}$ after the 
A

\begin{tabular}{l|cccccc|} 
& 0 or 15 FS & Acquisition & Maintenance & Ext & CIR & Ext \\
\hline Exp. Day & 1 & $2-6$ & $7-15$ & $16-20$ & 21 & 22 \\
Context & SHOCK & METH & METH & METH & METH & METH \\
\cline { 2 - 7 }
\end{tabular}

B
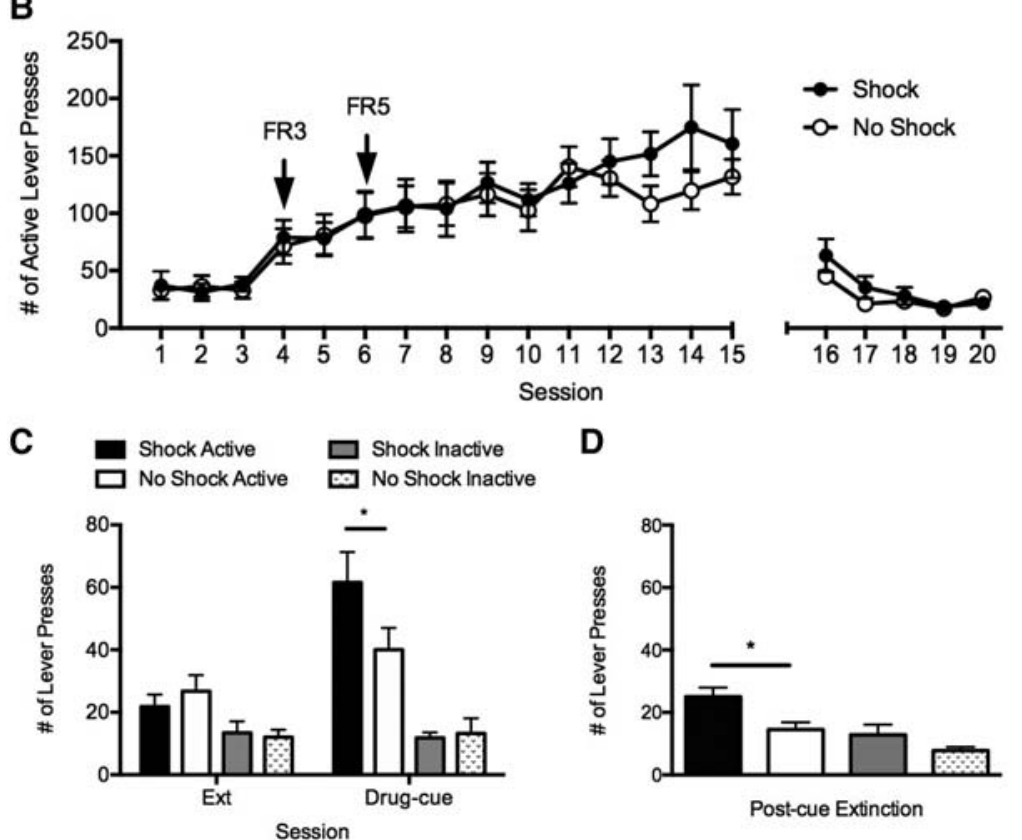

D

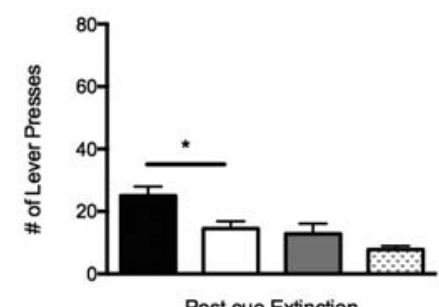

Figure 6. Effects of shock delivered prior to acquisition of methamphetamine seeking on acquisition, extinction, and cue-induced reinstatement. $(A)$ Overview of the design of Experiment 5 . Rats received 0 (Group No Shock; $n=8$ ) or 15 shocks (Group Shock; $n=7$ ) in a different context (SHOCK) prior to acquisition of methamphetamine seeking (METH). (B) There were no effects of the battery of shocks on acquisition or extinction. (C) Rats with a history of shock showed greater cue-induced reinstatement following extinction. $(D)$ This effect persisted to an extinction session the next day during which the cue was not presented. $\left(^{*}\right) P<0.05$.

battery of footshocks. These findings suggest that there may be an interaction between a past experience of stress and exposure to a cue previously associated with drugs that causes a persistent resistance to extinction of drug-seeking.

Our finding that a battery of shocks before or during acquisition may confer an increased vulnerability to reinstatement in response to cues previously paired with drug is also consistent with human studies of addiction and PTSD. A meta-analysis of cue-induced reactivity found that the effect size for self-reported cravings in addicts following exposure to drug-related cues was large across a wide range of drugs, arguing in favor of the importance of a model of heightened cue-induced reactivity (Carter and Tiffany 1999). It has also been shown that PTSD symptom severity correlates with self-reports of cue-elicited craving in comorbid individuals (Saladin et al. 2003). This may explain in part why individuals with anxiety disorders have an increased vulnerability to relapse, even following long periods of abstinence, especially in response to previously drug-paired cues (Bradizza et al. 2006). Our experiments demonstrate in rodents that this heightened cue-induced reactiv-
B

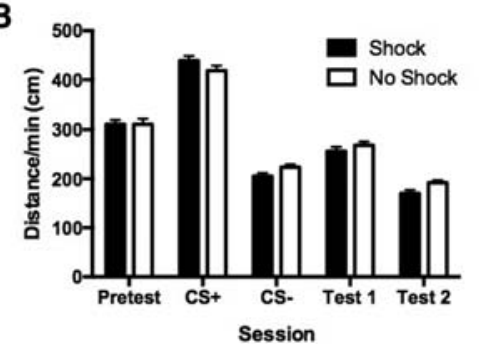

\begin{tabular}{|c|c|c|c|c|c|c|c|c|c|c|c|c|}
\hline A & Pretest & $\begin{array}{l}\text { CS+ } \\
\text { (coc) }\end{array}$ & $\begin{array}{c}\text { CS- } \\
\text { (saline) }\end{array}$ & $\begin{array}{l}\text { CS+ } \\
\text { (coc) }\end{array}$ & $\begin{array}{c}\text { CS- } \\
\text { (saline) }\end{array}$ & $\begin{array}{l}\text { CS+ } \\
\text { (coc) }\end{array}$ & $\begin{array}{c}\text { CS- } \\
\text { (saline) }\end{array}$ & $\begin{array}{l}\text { CS+ } \\
\text { (coc) }\end{array}$ & $\begin{array}{c}\text { CS- } \\
\text { (saline) }\end{array}$ & $\begin{array}{c}0 \text { or } 15 \\
\text { Footshocks }\end{array}$ & $\begin{array}{c}\text { Test } \\
1\end{array}$ & $\begin{array}{c}\text { Test } \\
\mathbf{2}\end{array}$ \\
\hline & 1 & 2 & 3 & 4 & 5 & 6 & 7 & 8 & 9 & 10 & 10 & $\overline{11}$ \\
\hline nter & CPP & CPP & CPP & CPP & CPP & CPP & CPP & CPP & CPP & SHOCK & CPP & CPP \\
\hline
\end{tabular}

ity persists long-term and interferes with the extinction of drug-seeking behaviors.

Massive footshock produced significantly elevated levels of CORT relative to exposure only controls immediately following footshock, but these levels normalized quickly and remained at baseline for 5 wk post footshock. This five-wk range was selected to investigate whether CORT levels were elevated during tests of reinstatement in Experiments 4 and 5, thus driving the enhancements in cued responding. In addition, a DEX challenge revealed that a single bout of massive footshock did not produce an alteration to the HPA axis's ability to provide reliable negative feedback. This falls in agreement with human literature that individuals with PTSD do not exhibit chronically elevated levels of cortisol (e.g., Meewisse et al. 2007; Yehuda and Seckl 2011). Because we did not sample blood at shorter time points $(30,60,90$ min) following footshock it is unclear when exactly CORT is normalized within this study. However, we were primarily interested in investigating long-term changes in CORT that may be responsible for our observed enhancements in cued-responding. Because CORT levels over time remain the same between groups and there is no difference between responses to dexamethasone it is unlikely that changes to the HPA or CORT system in general are responsible for this effect. It is also worth noting that the fear assessment to the massive footshock-associated context occurred nearly $7 \mathrm{wk}$ following footshock, suggesting the massive footshock protocol used in these studies produces persistent alterations in fear behavior, consistent with previous reports (e.g., Rau and Fanselow 2009).

Our findings reflect a novel, interactive model of fear conditioning and drug-seeking that demonstrates the ability of stress
Figure 7. Effects of shock on expression of cocaine-induced CPP in mice. $(A)$ Overview of the design of Experiment 6. Mice received pretest, $\mathrm{CS}+$, and $\mathrm{CS}$ - conditioning trials over $5 \mathrm{~d}$, followed by 0 (Group No Shock; $n=20$ ) or 15 (Group Shock; $n=16$ ) shocks in a different context, followed by tests in the CPP context. $(B)$ Activity during Pretest, conditioning trials (CS + with cocaine; CS - with saline), and postshock tests. (C) Relative to the No Shock controls, mice that were shocked showed increased preference for the CS+ (cocaine-paired) floor immediately (Test 1$)$ and $24 \mathrm{~h}$ after shock (Test 2$) .\left(^{*}\right) P<0.05$. 


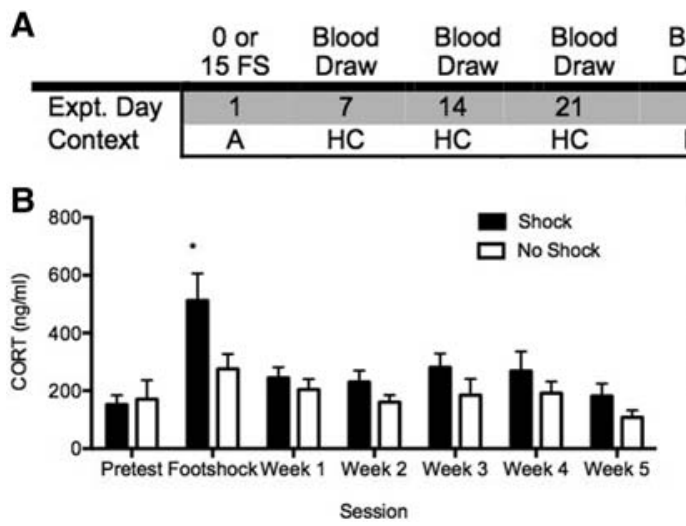

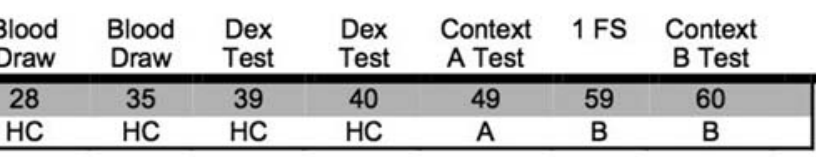
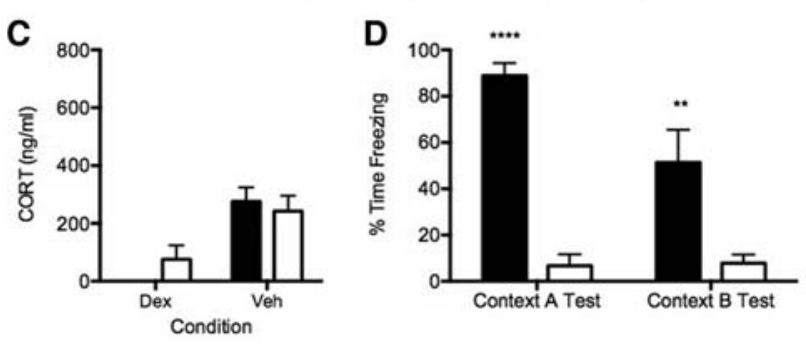

Figure 8. Effects of shock on CORT levels. (A) Overview of the design of Experiment 7. Rats received 0 (Group No Shock; $n=7$ ) or 15 (Group Shock; $n=7$ ) footshocks (FS), followed by blood draws on the day of shock and weekly thereafter in the homecage (HC). SEFL was tested on Days 49-60. (B) Massive shock increased corticosterone (CORT) relative to exposure only controls, but this increase returned to near baseline levels during subsequent weeks. (C) The synthetic corticosteroid DEX ( $50 \mu \mathrm{g} / \mathrm{kg}$, SQ) induced potent negative feedback in both groups of animals. $(D)$ The SEFL effect occurred during a test 60 $\mathrm{d}$ after the initial battery of shock (Context B Test. $\left({ }^{\star *}\right) P<0.01,\left({ }^{* * * *}\right) P<0.0001$ ).

during a single session in a specific context to lead to persistent changes in drug-seeking in another context. These changes include reinstatement to drug-related cues and a persistent drugseeking response following cue-induced reinstatement. Clinical studies have shown that trauma-focused treatments are significantly more effective at improving SUDs in individuals with a comorbid PTSD diagnosis (Hien et al. 2010), suggesting that our preclinical approach could be used in situations that may better model the clinical condition (Hariri and Holmes 2015). Because this model involves measurable behavioral responses in the stress-associated context (freezing) and the drug-associated context (drug-seeking), it can serve as a tool for understanding the relation between learned fears and substance abuse, as well as the potential to test novel therapeutic agents designed to weaken fear and attenuate reinstatement in the comorbid condition.

\section{Materials and Methods}

\section{Animals}

One hundred and twenty-one male Long Evans rats (Charles River) that weighed $275-300 \mathrm{~g}(\sim 9-11 \mathrm{wk}$ of age) at the start of the experiments were pair housed in a temperature $\left(22^{\circ} \mathrm{C} \pm 1^{\circ} \mathrm{C}\right)$ and humidity-controlled (70\%) vivarium and were maintained on a 12/12 h light-dark cycle (6:00 a.m./6:00 p.m.). Following surgery, animals were single housed, and $3 \mathrm{~d}$ prior to the initiation of selfadministration training animals were food restricted to $\sim 90 \%$ free feeding body weight. Rats that did not receive jugular catheter surgery were not food restricted, but were single housed prior to the onset of behavioral testing.

Thirty-six adult, male C57BL/6J mice (Jackson Laboratory) weighing $\sim 27 \mathrm{~g}$ at the start of the experiment were housed four to a cage on a $12 \mathrm{~h}$ light-dark cycle (lights on at $6 \mathrm{a} . \mathrm{m}$ ). Mice were 11-16 wk of age and were given ad libitum access to food and water. Mice were handled and weighed daily for $5 \mathrm{~d}$ prior to the start of the experiment. Housing conditions and treatment of these animals were approved by the Oregon Health \& Science University Institutional Animal Care and Use Committee and conducted in accordance with the ethical guidelines of the National Institutes of Health.

\section{Drugs}

Methamphetamine (Sigma-Aldrich) was dissolved in sterile saline and administered IV as a $0.06 \mathrm{mg} / \mathrm{kg} /$ infusion over $5 \mathrm{sec}$. Cocaine hydrochloride (COC; Sigma-Aldrich) was dissolved in sterile saline and administered at a dose of $20 \mathrm{mg} / \mathrm{kg}$ via an intraperi- toneal (IP) injection. Dexamethasone (DEX; Sigma-Aldrich) was dissolved in $0.01 \%$ propylene glycol injected subcutaneously at a dose of $50 \mu \mathrm{g} / \mathrm{kg}$.

\section{Apparatus}

In all experiments, drug seeking (self-administration or conditioned place preference) occurred in both a different room and chamber from massive footshock.

\section{Rat self-administration and fear conditioning apparatus (Experiments 1, 2, 3, 4, 5, and 7)}

\section{Context 1}

Methamphetamine self-administration (Experiments 2, 4, and 5) sessions were conducted in operant conditioning chambers (Med Associates) (exterior dimensions: $31.8 \mathrm{~cm} \mathrm{~L} \times 25.4 \mathrm{~cm} \mathrm{~W} \times$ $34.3 \mathrm{~cm} \mathrm{H}$ ) housed within sound-attenuating cubicles (Med Associates). All self-administration sessions lasted for $2 \mathrm{~h}$. The syringe pumps (Med Associates) that delivered drug were located outside the sound-attenuating chambers. Grid floors composed of 19 stainless steel rods $(0.48 \mathrm{~cm}$ diameter with $1.6 \mathrm{~cm}$ spacing between them) were connected to shocker/scramblers (Med Associates) that delivered footshock. Each chamber was outfitted with two retractable levers, a stimulus light above each lever, and a houselight that was illuminated throughout the duration of every session. Between cohorts, 95\% EtOH was used to clean these chambers.

These boxes were also used to deliver massive footshock in Experiment 1 (SEFL replication) and Experiment 3 (selfadministration of EtOH) with the levers retracted and the houselight illuminated throughout the session.

\section{Context 2}

Operant conditioning chambers (exterior dimensions: $31.8 \mathrm{~cm} \mathrm{~L} \times$ $25.4 \mathrm{~cm} \mathrm{~W} \times 26.7 \mathrm{~cm} \mathrm{H}$, Med Associates) housed within sound-attenuating chambers (Med Associates) were located in a different room from Context 1 chambers. These chambers had identical grid floors to Context 1 . When used for the self-administration of EtOH these chambers were outfitted with two nonretractable levers with a stimulus light above each lever, a stainless steel cup between the levers into which EtOH was dispensed, and a houselight centered on the top panel.

These chambers were also used to deliver massive footshock in Experiment 1 (SEFL replication), Experiment 2 (freezing in METH context), Experiment 4 (footshock before self-administration of METH), Experiment 5 (footshock during self-administration of METH), and Experiment 6 (mouse CPP). For Experiment 6, the 
floors were exchanged with mouse-specific floors as described below. When used for these experiments the levers, stimulus lights, and stainless steel cup were removed so that only steel paneled walls and a houselight, which remained illuminated throughout the session, remained. Between cohorts, $0.5 \%$ bleach was used to clean the chambers.

\section{Mouse conditioned place preference and fear conditioning (Experiment 6)}

\section{Apparatus}

Conditioned place preference (CPP) was performed using an unbiased procedure in unbiased apparatus (see Cunningham et al. 2006) that consisted of $30 \times 15 \times 15 \mathrm{~cm}$ clear acrylic walls divided in half by another clear acrylic wall, resulting in two $15 \times 15 \times$ $15 \mathrm{~cm}$ compartments during acquisition. The bottom was supported by interchangeable half-floors composed of $2.3-\mathrm{mm}$ stainless steel rods mounted $6.4 \mathrm{~mm}$ apart (GRID floor) or perforated stainless steel with $6.4-\mathrm{mm}$ round holes on $9.5-\mathrm{mm}$ staggered centers (HOLE floor). The CPP apparatus was located within a melamine sound-attenuating shell. A camera was mounted to the ceiling of the sound-attenuating chamber and mouse position in the apparatus was recorded by an automated tracking program (Noldus Ethovision).

Fear conditioning occurred in a novel environment in a separate room from the CPP context using modified operant boxes (Context 2; Med Associates) housed within sound-attenuating chambers. Floors consisted of 36 parallel stainless steel rods with a $0.327 \mathrm{~cm}$ diameter. The walls of the chamber were bare except for a houselight that remained illuminated for the duration of the session.

\section{General procedures}

\section{Jugular catheter surgery (Experiments 2, 4, and 5)}

Catheter assembly. Jugular catheters were made of $12 \mathrm{~cm}$ long silastic tubing (0.037 mm ID, $0.94 \mathrm{~mm}$ OD; Dow Corning) with small beads of $100 \%$ silicone rubber sealant at 8.5 and $9 \mathrm{~cm}$, respectively. One end of the catheter was inserted into the right jugular vein and run subcutaneously below the front right leg to exit the back between the shoulder blades. A stainless steel guide cannula (22 ga; Plastics One) was inserted into an elastomer self-administration harness (Instech Laboratories) and the jugular catheter was attached to the cannula within the harness.

Surgery. Anesthesia was induced with an intramuscular (IM) injection of ketamine/xylazine $(85 \mathrm{mg} / \mathrm{kg} ; 10 \mathrm{mg} / \mathrm{kg})$, and was maintained throughout the duration of the surgery by vaporized isoflurane $(1 \%)$. Catheters were implanted and connected to the harnesses as described above. Following surgery animals received a daily IV infusion of $0.1 \mathrm{~mL} 100$ unit heparin and the antibiotic Timentin $(238 \mathrm{mg} / \mathrm{mL})$. On days when animals performed self-administration, an intravenous (IV) infusion of $0.1 \mathrm{~mL} 10$ unit heparin was also administered prior to the session. Catheter patency was confirmed via $0.1 \mathrm{~mL}$ IV injection of $10 \mathrm{mg} / \mathrm{mL}$ sodium brevital before training began.

\section{Self-administration of methamphetamine (Experiments 2, 4, and 5)}

In all experiments, self-administration sessions (acquisition, extinction, and reinstatement) lasted for $2 \mathrm{~h}$. At the onset of each session a houselight was illuminated and two retractable levers were inserted into the chamber. One lever was designated the active lever, and upon completion of the fixed ratio (FR) requirement 88.5 $\mu \mathrm{L}$ of methamphetamine was administered IV over $5 \mathrm{sec}(0.06 \mathrm{mg} /$ $\mathrm{kg}$ /infusion), and the stimulus light above the active lever was concurrently illuminated for $5 \mathrm{sec}$. The inactive lever also had a stimulus light above it; however, pressing the inactive lever did not result in any programmed consequences. Levers were counterbalanced across animals. During extinction (ext) sessions, presses on either lever did not result in any programmed consequences.
During cue-induced reinstatement sessions a press on the active lever resulted in the activation of the stimulus light above the active lever for $5 \mathrm{sec}$, but no drug was delivered. Animals received a single self-administration session per day.

\section{Experiment 1: Replication of the SEFL effect}

Twenty-one rats received SEFL treatment following the methods of Rau et al. (2005). Animals received 0, 1, 4 (intershock interval [ISI] of 3-7 min), or $151 \mathrm{~mA}$ (ISI of $4-8 \mathrm{~min}$ ), $1 \mathrm{sec}$ footshocks in Context A; session durations were 93 min for the 0 and 15 shock groups, 3 min $44 \mathrm{sec}$ for the 1 shock group, and $23 \mathrm{~min}$ for the 4 shock group. $24 \mathrm{~h}$ later, fear to Context A was assessed during an $8 \mathrm{~min} 32 \mathrm{sec}$ nonreinforced session. $24 \mathrm{~h}$ later animals received a single $1 \mathrm{~mA}$ footshock in Context B (delivered at $3 \mathrm{~min} 12 \mathrm{sec}$ of a 3 min 48 sec session), and fear to Context B was assessed $24 \mathrm{~h}$ later in an $8 \mathrm{~min} 32 \mathrm{sec}$ nonreinforced session. Contexts were counterbalanced between Contexts 1 and 2. Fear conditioning was measured by sampling freezing behavior, defined as the lack of movement except that which is required for breathing, every $8 \mathrm{sec}$.

\section{Experiment 2: SEFL effect in a context associated with methamphetamine}

Rats were trained to lever press for methamphetamine in the selfadministration context (METH; Context 1 in this experiment) during 9 FR1 sessions, followed by 19 FR5 sessions, followed by three 2-h extinction sessions, in which responding on either lever had no programmed consequences. Twenty-four hours after the final extinction session, animals received 0 or 15 footshocks in the shock context (SHOCK; Context 2 in this experiment) over the course of $93 \mathrm{~min} .24 \mathrm{~h}$ after footshock animals were returned to the METH context with levers retracted. After 5 min all animals received a single, 1 -sec $1 \mathrm{~mA}$ footshock, after which the levers were immediately extended. Reinstatement following the single footshock was assessed in extinction, and freezing behavior in the 5 min pre- and post-footshock was recorded. The 13 rats that remained patent throughout the duration of this study were included in the analysis.

\section{Experiment 3: SEFL effect in a context associated with ethanol}

Sixteen rats were trained to lever press for $10 \% \mathrm{EtOH}$ using a sucrose fading procedure. Rats were given ad libitum access to food and water while in the homecage (animals were water restricted up to $20 \mathrm{~h}$ prior to sessions 4 and 5 to promote acquisition). Sessions were $2 \mathrm{~h}$ long and occurred every other day. Pressing the active lever caused a syringe pump to deliver $0.1 \mathrm{~mL}$ of liquid into a stainless steel cup over $1.66 \mathrm{sec}$ and activated a cue light above the lever for $1.66 \mathrm{sec}$. Total rewards were limited to 200 , equivalent to $20 \mathrm{~mL}$ of solution. Animals were trained to respond to sucrose alone (10\%) for eight sessions on an FR1 schedule (lever press requirements were set to FR1 for the duration of the experiment, with the exception of the six final sessions, which were FR5) in the EtOH context (Context 2 in this experiment). Ethanol was phased in according to the following schedule: $10 \%$ sucrose $/ 2 \% \mathrm{EtOH}$ for three sessions, $10 \%$ sucrose/5\% EtOH for three sessions, $5 \%$ sucrose $/ 5 \%$ EtOH for three sessions, 5\% sucrose $10 \% \mathrm{EtOH}$ for three sessions, $2 \%$ sucrose $/ 10 \% \mathrm{EtOH}$ for three sessions, $1 \%$ sucrose $/ 10 \%$ EtOH for three sessions, $10 \%$ EtOH alone for six sessions, and $10 \% \mathrm{EtOH}$ on an FR5 schedule for six sessions.

Seven days after the final FR5 session animals were given either 0 or 15 footshocks in the SHOCK context (Context 1 in this experiment), then were returned to the EtOH self-administration context (EtOH context; Context 2 in this experiment) and given a $2 \mathrm{~h} 10 \% \mathrm{EtOH}$ FR5 session. Animals were allowed to selfadminister $10 \% \mathrm{EtOH}$ on an FR5 schedule for seven additional days, followed by four 2-h extinction sessions. Twenty-four hours after the final extinction session animals were tested for cued reinstatement during which a press on the previously active lever resulted in the $1.66 \mathrm{sec}$ illumination of the cue light above the lever, but no drug delivery. Sixty-five days after massive 
footshock in the SHOCK context animals received a single, $1 \mathrm{~mA}$ footshock delivered 5 min into a 15 min session in the EtOH context.

\section{Experiment 4: massive footshock during acquisition of methamphetamine self-administration in a different context}

Rats were trained to respond for methamphetamine over 4 FR1 sessions, followed by 4 FR3 sessions, followed by eight FR5 sessions in the METH context (Context 1 in this experiment). Prior to the seventh FR5 session (the 15th session of 30 total self-administration sessions), animals received either 0 or 15 footshocks in the SHOCK context (Context 2 in this experiment). Immediately following footshock animals were returned to the METH context and given an FR5 session. Following the eighth FR5 session the response requirement was increased to FR10 for 14 sessions, followed by three extinction sessions. Twenty-four hours after the last extinction session, animals were restrained (DecapiCones) within the METH context for $5 \mathrm{~min}$, and were then allowed to lever press for $2 \mathrm{~h}$ in extinction. Animals then received four additional extinction sessions, followed by a test of cue-induced reinstatement, followed by six additional extinction sessions. After an additional $5 \mathrm{~d}$ in the homecage, rats were returned to the operant chambers and retention was tested in extinction. Animals then received 13 additional extinction sessions, followed by a test of footshock-induced reinstatement (10 sec after placement into the chamber $10,0.5 \mathrm{~mA}$ shocks were delivered, variable ISI 10-70 sec, levers extended immediately following final shock and animals were allowed to lever press for the remaining $2 \mathrm{~h}$ session). The 11 animals that remained patent throughout the duration of the study were included in the analysis.

\section{Experiment 5: massive footshock prior to acquisition of methamphetamine self-administration in a different context}

Rats were exposed to 0 or 15 footshocks as described above in the SHOCK context (Context 2 in this experiment). Self-administration of methamphetamine began $24 \mathrm{~h}$ later in the METH context (Context 1 in this experiment). Animals were trained to lever press for methamphetamine during three FR1 sessions, two FR3 sessions, and 10 FR5 sessions. Animals were then extinguished over five extinction sessions, followed by a cue-induced reinstatement test and one additional extinction session. The 15 animals that remained patent throughout the duration of the study were included in the analysis.

\section{Experiment 6: massive footshock in a different context prior to cocaine CPP tests}

CPP procedures followed Hitchcock et al. (2014). Mice were given a 5 -min pretest in which they had access to both floors of the CPP chamber. Mice were then counterbalanced relative to floor preference to match time on the CS+ floor for the mice to be assigned to shock or no shock groups. Twenty-four hours following the pretest, all mice received an IP injection of cocaine (COC) and were placed on the CS+ floor (GRID or HOLE, counterbalanced). The following day, mice received an IP injection of saline alone and were placed on the CS- floor (HOLE or GRID, counterbalanced). Animals received six additional conditioning sessions over the next $6 \mathrm{~d}$, with a single conditioning trial per day for a total of $4 \mathrm{CS}+$ and 4 CS- pairings. During conditioning, animals were restricted to one floor type and half the total area of the apparatus by placing a clear Plexiglas divider between the two floor types. Conditioning sessions were $5 \mathrm{~min}$ in duration.

Three days following the final conditioning session mice were placed into the novel fear context described above. Mice in the Shock group $(n=16)$ received 15 intermittent, unsignaled footshocks (0.5 mA, $0.5 \mathrm{sec}$, variable ISI 4-8 $\mathrm{min})$ over a 93-min period. Control mice in the No Shock group $(n=20)$ were exposed to the context alone for an equivalent amount of time. Immediately after the fear conditioning session, mice were taken to the CPP context, given an IP injection of saline, and placed in the CPP chamber with both floors (GRID and HOLE) accessible for 15 min (Test 1). This test was repeated $24 \mathrm{~h}$ later (Test 2).

\section{Experiment 7: the effect of massive shock on corticosterone and hypothalamic-pituitary-adrenal axis function}

Blood samples were collected once prior to the onset of SEFL training. Rats then received either $0(n=7)$ or $15(n=7)$ footshocks as described above in Context $\mathrm{A}$, and blood was drawn immediately following removal from the chamber. Blood samples were then collected once per week for $5 \mathrm{wk}$ to mirror the length of time between footshock and the cue-induced enhancements seen in Experiments 4 and 5. All blood samples were collected before 12:00 p.m. through the saphenous vein. Blood samples were mixed with $2 \mu \mathrm{L} 0.5 \mathrm{MM}$ EDTA, spun at 8,000 RPM for $15 \mathrm{~min}$, and plasma was collected and stored at $-80^{\circ} \mathrm{C}$ until processing. CORT levels were determined using a radioimmunoassay (RIA) kit (MP Biomedicals).

DEX is a synthetic corticosteroid that induces negative feedback of the hypothalamic-pituitary-adrenal (HPA) axis, decreasing levels of cortisol (Yehuda et al. 1993). Five weeks following footshock rats received counterbalanced injections of DEX or Vehicle over $2 \mathrm{~d}$ and blood samples were collected $6 \mathrm{~h}$ following administration. All blood draws were taken before 12:00 p.m.

One week following DEX administration animals were returned to Context A and were tested for contextual freezing during an 8.5 min test. One week later animals received a single, $1 \mathrm{~mA}$ footshock in Context B and $24 \mathrm{~h}$ later were tested for contextual freezing during an 8.5 min test. Contexts A and B were counterbalanced between Contexts 1 and 2 .

\section{Acknowledgments}

This work was supported by grants from the U.S. Department of the Army (DOD-TATRC W81XWH-14-2-0143), NIH (DA025922), and the Methamphetamine Abuse Research Center (DA018165) to K. M.L., an NIH T32 DA007262 and an American Psychological Association Dissertation Award to C.L.P.

\section{References}

American Psychiatric Association. 2013. Diagnostic and statistical manual of mental disorders, 5th ed. American Psychiatric Publishing, Arlington, VA.

Back SE, Dansky BS, Coffey SF, Saladin ME, Sonne SC, Brady KT. 2000. Cocaine dependence with and without posttraumatic stress disorder: a comparison of substance use, trauma history, and psychiatric comorbidity. Am J Addict 9: 51-62.

Blouin AM, Sillivan SE, Joseph NF, Miller CA. 2016. The potential of epigenetics in stress-enhanced fear learning models of PTSD. Learn Mem 23: $576-586$.

Bouton ME, Bolles RC. 1980. Conditioned fear assessed by freezing and by the suppression of three different baselines. Anim Learn Behav 8: $429-434$.

Boutrel B, Kenny PJ, Specio SE, Martin-Fardon R, Markou A, Koob GF, de Lecea L. 2005. Role for hypocretin in mediating stress-induced reinstatement of cocaine-seeking behavior. Proc Natl Acad Sci 102: 19168-19173.

Bradizza CM, Stasiewicz PR, Paas ND. 2006. Relapse to alcohol and drug use among individuals diagnosed with co-occurring mental health and substance use disorders: a review. Clin Psychol Rev 26: 162-178.

Brown PJ, Stout RL, Mueller T. 1999. Substance use disorder and posttraumatic stress disorder comorbidity: addiction and psychiatric treatment rates. Psychol Addict Behav 13: 115-122.

Burns MN, Lehman KA, Milby JB, Wallace D, Schumacher JE. 2010. Do PTSD symptoms and course predict continued substance use for homeless individuals in contingency management for cocaine dependence? Behav Res Ther 48: 588-598.

Carter BL, Tiffany ST. 1999. Meta-analysis of cue-reactivity in addiction research. Addiction 94: 327-340.

Cunningham CL, Gremel CM, Groblewski PA. 2006. Drug-induced conditioned place preference and aversion in mice. Nat Protoc 1: 1662-1670.

Eggleston AM, Calhoun PS, Svikis DS, Tuten M, Chisolm MS, Jones HE. 2009. Suicidality, aggression, and other treatment considerations among pregnant, substance-dependent women with posttraumatic stress disorder. Compr Psychiatry 50: 415-423. 
Erb S, Salmaso N, Rodaros D, Stewart J. 2001. A role for the CRF-containing pathway from central nucleus of the amygdala to bed nucleus of the stria terminalis in the stress-induced reinstatement of cocaine seeking in rats. Psychopharmacology (Berl) 158: 360-365.

Fanselow MS. 1982. The postshock activity burst. Learn Behav 10: 448-454.

Ferland CL, Reichel CM, McGinty JF. 2016. Effects of oxytocin on methamphetamine-seeking exacerbated by predator odor pre-exposure in rats. Psychopharmacology (Berl) 233: 1015-1024.

Goeders NE, Guerin GF. 1994. Non-contingent electric footshock facilitates the acquisition of intravenous cocaine self-administration in rats. Psychopharmacology (Berl) 114: 63-70.

Hariri AR, Holmes A. 2015. Finding translation in stress research. Nat Neurosci 18: $1347-1352$

Hien DA, Jiang H, Campbell AN, Hu MC, Miele GM, Cohen LR, Brigham GS, Capstick C, Kulaga A, Robinson J, Suarez-Morales L. 2010. Do treatment improvements in PTSD severity affect substance use outcomes? A secondary analysis from a randomized clinical trial in NIDA's Clinical Trials Network. Am J Psychiatry 167: 95-101.

Hitchcock LN, Cunningham CL, Lattal KM. 2014. Cue configuration effects in acquisition and extinction of a cocaine-induced place preference. Behav Neurosci 128: 217-227.

Kim JJ, Jung MW. 2006. Neural circuits and mechanisms involved in Pavlovian fear conditioning: a critical review. Neurosci Biobehav Rev 30: $188-202$.

Kubiak SP. 2004. The effects of PTSD on treatment adherence, drug relapse, and criminal recidivism in a sample of incarcerated men and women. Res Soc Work Pract 14: 424-433.

Lê AD, Poulos CX, Harding S, Watchus J, Juzytsch W, Shaham Y. 1999. Effects of naltrexone and fluoxetine on alcohol self-administration and reinstatement of alcohol seeking induced by priming injections of alcohol and exposure to stress. Neuropsychopharmacology 21: 435-444.

Lewis CR, Staudinger K, Scheck L, Olive MF. 2013. The effects of maternal separation on adult methamphetamine self-administration, extinction, reinstatement, and MeCP2 immunoreactivity in the nucleus accumbens. Front Psychiatry 4: 55

Liu X, Weiss F. 2002. Additive effect of stress and drug cues on reinstatement of ethanol seeking: exacerbation by history of dependence and role of concurrent activation of corticotropin-releasing factor and opioid mechanisms. INeurosci 22: 7856-7861.

Long VA, Fanselow MS. 2012. Stress-enhanced fear learning in rats is resistant to the effects of immediate massed extinction. Stress 15: 627-636.

Maren S, Phan KL, Liberzon I. 2013. The contextual brain: implications for fear conditioning, extinction and psychopathology. Nat Rev Neurosci 14: $417-428$.

McCauley JL, Killeen T, Gros DF, Brady KT, Back SE. 2012. Posttraumatic stress disorder and co-occurring substance use disorders: advances in assessment and treatment. Clin Psychol 19: 283-304.

McFarland K, Davidge SB, Lapish CC, Kalivas PW. 2004. Limbic and motor circuitry underlying footshock-induced reinstatement of cocaine-seeking behavior. J Neurosci 24: $1551-1560$.

McFarlane AC. 1998. Epidemiological evidence about the relationship between PTSD and alcohol abuse: the nature of the association. Addict Behav 23: 813-825.

Meewisse ML, Reitsma JB, de Vrie GJ, Gersons BP, Olff M. 2007. Cortisol and post-traumatic stress disorder in adults. Br J Psychiatry 191: 387-392.

Meyer ME, Long V, Fanselow MS, Spigelman I. 2013. Stress increases voluntary alcohol intake, but does not alter established drinking habits in a rat model of posttraumatic stress disorder. Alcohol Clin Exp Res 37: 566-574.

Najt P, Fusar-Poli P, Brambilla P. 2011. Co-occurring mental and substance abuse disorders: a review on the potential predictors and clinical outcomes. Psychiatry Res 186: 159-164.

Ouimette PC, Brown PJ, Najavits LM. 1998. Course and treatment of patients with both substance use and posttraumatic stress disorders. Addict Behav 23: 785-795.

Piazza PV, Deminiere JM, le Moal M, Simon H. 1990. Stress- and pharmacologically-induced behavioral sensitization increases vulnerability to acquisition of amphetamine self-administration. Brain Res 514: 22-26.

Quadros IMH, Miczek KA. 2009. Two modes of intense cocaine bingeing: increased persistence after social defeat stress and increased rate of intake due to extended access conditions in rats. Psychopharmacology (Berl) 206: 109-120.
Ramsey NF, Van Ree JM. 1993. Emotional but not physical stress enhances intravenous cocaine self-administration in drug-naïve rats. Brain Res 608: $216-222$.

Rau V, Fanselow MS. 2009. Exposure to a stressor produces a long lasting enhancement of fear learning in rats. Stress 12: 125-133.

Rau V, DeCola JP, Fanselow MS. 2005. Stress-induced enhancement of fear learning: an animal model of posttraumatic stress disorder. Neurosci Biobehav Rev 29: 1207-1223.

Redila VA, Chavkin C. 2008. Stress-induced reinstatement of cocaine seeking is mediated by the $\mathrm{\kappa}$ opioid system. Psychopharmacology (Berl) 200: $59-70$.

Roberts NP, Roberts PA, Jones N, Bisson JI. 2015. Psychological interventions for post-traumatic stress disorder and comorbid substance use disorder: a systemic review and meta-analysis. Clin Psychol Rev 38: $25-38$.

Saladin ME, Drobes DJ, Coffey SF, Dansky BS, Brady KT, Kilpatrick DG. 2003. PTSD symptom severity as a predictor of cue-elicited drug craving in victims of violent crime. Addict Behav 28: 1611-1629.

Sanchez CJ, Sorg BA. 2001. Conditioned fear stimuli reinstate cocaine-induced conditioned place preference. Brain Res 908: 86-92.

Sanchez CJ, Bailie TM, Wu W, Li N, Sorg BA. 2003. Manipulation of dopamine d1-like receptor activation in the rat medial prefrontal cortex alters stress- and cocaine-induced reinstatement of conditioned place preference behavior. Neuroscience 119: 497-505.

Schindler AG, Li S, Chavkin C. 2010. Behavioral stress may increase the rewarding valence of cocaine-associated cues through a dynorphin/ $\kappa$-opioid receptor-mediated mechanism without affecting associative learning or memory retrieval mechanisms. Neuropsychopharmacology 35: 1932-1942.

Shaham Y. 1993. Immobilization stress-induced oral opioid self-administration and withdrawal in rats: role of conditioning factors and the effect of stress on "relapse" to opioid drugs. Psychopharmacology (Berl) 111: 477-485.

Shaham Y, Stewart J. 1994. Exposure to mild stress enhances the reinforcing efficacy of intravenous heroin self-administration in rats. Psychopharmacology (Berl) 114: 523-527.

Shaham Y, Erb S, Leung S, Buczek Y, Stewart J. 1998. CP-154,526, a selective, non-peptide antagonist of the corticotropin-releasing factor 1 receptor attenuates stress-induced relapse to drug seeking in cocaine- and herointrained rats. Psychopharmacology 137: 184-190.

Shaham Y, Erb S, Stewart J. 2000. Stress-induced relapse to heroin and cocaine seeking in rats: a review. Brain Res Brain Res Rev 33: 13-33.

Shalev U, Highfield D, Yap J, Shaham Y. 2000. Stress and relapse to drug seeking in rats: studies on the generality of the effect. Psychopharmacology (Berl) 150: 337-346.

Smith RC, Blumenthal H, Badour C, Feldner MT. 2010. An investigation of relations between crystal methamphetamine use and posttraumatic stress disorder. Addict Behav 35: 625-627.

Sonne SC, Back SE, Zuniga CD, Randall CL, Brady KT. 2003. Gender differences in individuals with comorbid alcohol dependence and post-traumatic Stress Disorder. Am J Addict 12: 412-423.

Stewart SH. 1996. Alcohol abuse in individuals exposed to trauma: a critical review. Psychol Bull 120: 83-112.

Tate SR, Brown SA, Unrod M, Ramo DE. 2004. Context of relapse for substance-dependent adults with and without comorbid psychiatric disorders. Addict Behav 29: 1707-1724.

Tidey JW, Miczek KA. 1997. Acquisition of cocaine self-administration after social stress: role of accumbens dopamine. Psychopharmacology (Berl) 130: 203-212.

Tipps ME, Raybuck JD, Lattal KM. 2014. Substance abuse, memory, and post-traumatic stress disorder. Neurobiol Learn Mem 112: $87-100$.

Yehuda R, Seckl J. 2011. Minireview: stress-related psychiatric disorders with low cortisol levels: a metabolic hypothesis. Endocrinology 152: $4496-4503$.

Yehuda R, Southwick SM, Krystal JH, Bremner D, Charney DS, Mason JW. 1993. Enhanced suppression of cortisol following dexamethasone administration in posttraumatic stress disorder. Am J Psychiatry 150: 83-83.

Received January 24, 2017; accepted in revised form July 8, 2017. 


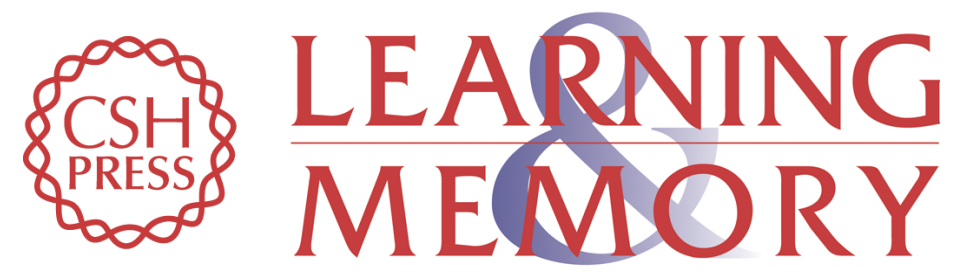

\section{Persistent effects of acute stress on fear and drug-seeking in a novel model of the comorbidity between post-traumatic stress disorder and addiction}

Christie L. Pizzimenti, Tom M. Navis and K. Matthew Lattal

Learn. Mem. 2017, 24:

Access the most recent version at doi:10.1101/Im.044164.116

Supplemental
Material http://learnmem.cshlp.org/content/suppl/2017/08/09/24.9.422.DC1

References This article cites 55 articles, 5 of which can be accessed free at: http://learnmem.cshlp.org/content/24/9/422.full.html\#ref-list-1

Creative This article is distributed exclusively by Cold Spring Harbor Laboratory Press for the Commons first 12 months after the full-issue publication date (see

License http://learnmem.cshlp.org/site/misc/terms.xhtml). After 12 months, it is available under a Creative Commons License (Attribution-NonCommercial 4.0 International), as described at http://creativecommons.org/licenses/by-nc/4.0/.

Email Alerting Receive free email alerts when new articles cite this article - sign up in the box at the Service top right corner of the article or click here. 